\title{
Água disponível em um Latossolo Vermelho argiloso e murcha fisiológica de culturas
}

\author{
Vilson A. Klein ${ }^{1}$, José M. Reichert ${ }^{2}$ \& Dalvan J. Reinert ${ }^{2}$
}

\begin{abstract}
RESUMO
Para a determinação do volume de água retido no solo e disponível às plantas, é imprescindível quantificar o teor de água do solo (TAS) na capacidade de campo (CC) e no ponto de murcha permanente (PMP). O objetivo deste trabalho foi comparar os valores do TAS na CC e no PMP determinados por distintos métodos. Utilizaram-se amostras de um Latossolo Vermelho. A CC foi obtida no campo com o método do perfil instantâneo e, no laboratório, com funis de placa porosa. O PMP foi determinado, em laboratório, como sendo o teor de água residual retida no potencial matricial de -1,5 MPa, em câmara de Richards e com medidor de potencial de ponto de orvalho WP4 PotentiaMeter. Para murcha das plantas, o TAS foi significativamente menor no método fisiológico que o determinado nas câmaras de Richards; entretanto, o teor de água do solo no PMP foi estatisticamente igual para a cultura do girassol e superior para o milho, quando comparado com aquele obtido pelo WP4. A água disponível diminuiu com o aumento na tensão para a estimativa da CC e com o método WP4, mas não diferiu do método fisiológico. Assim, o WP4 permitiu adequada estimativa do PMP e disponibilidade hídrica às plantas, em solo argiloso.
\end{abstract}

Palavras-chave: capacidade de campo, ponto de murcha permanente, retenção de água no solo

\section{Available water in a clayey Oxisol and physiological wilting of crops}

\begin{abstract}
To estimate available soil water to plants it is necessary to measure field capacity ( $\mathrm{FC}$ ) and permanent wilting point (PWP). The objective of this study was to compare soil moisture at FC and PWP measured by different methods. The soil used was a tropical Oxisol (Haplorthox). The FC was measured under field conditions, using the internal drainage method and in laboratory using porous plate funnel. The PWP was quantified in laboratory as the soil moisture at -1.5 MPa matric potential measured by pressure plate apparatus (Richards chamber) and by WP4 dewpoint Potentia Meter. The physiological PWP was measured using corn and sunflower plants, when they had three leaf pairs and showed irreversible wilting. The soil moisture for PWP based on the physiological method was smaller than soil moisture measured with the pressure plate apparatus; however, soil moisture for sunflower wilting was similar while for corn it was greater than that obtained with the WP4. The available water decreased with increase in water tension considered for estimating FC and with the WP4 method, but similar to one quantified with the physiological method. Thus, the WP4 allowed for adequate estimation of PWP and available water to plants in a clay soil.
\end{abstract}

Key words: field capacity, permanent wilting point, soil water retention

${ }^{1}$ Faculdade de Agronomia e Medicina Veterinária da Universidade de Passo Fundo (UPF). CEP 99001-970, Passo Fundo, RS. Fone: (54) 3312 8152. E-mail: vaklein@upf.br ${ }^{2}$ Departamento de Solos/UFSM, CEP 97105-900, Santa Maria, RS. Fone: (55) 3220 8108. Bolsista do CNPq. E-mails: dalvan@ccr.ufsm.br; reichert@ccr.ufsm.br 


\section{INTRODUÇÃO}

A quantificação da água disponível às plantas, situada entre a capacidade de campo (CC) e o ponto de murcha permanente (PMP), é necessária para o manejo da água do solo em agricultura irrigada, com reflexos nos cálculos da lâmina de água de irrigação; contudo, esses limites têm sido objeto de crítica e estudos (Reichardt, 1988; Carlesso, 1995; Souza \& Reichardt, 1996).

Para Veihmeyer \& Hendrickson (1949) a CC refere-se à quantidade de água retida pelo solo depois que o excesso tenha drenado e a taxa de movimento descendente haja decrescido acentuadamente. Em solos permeáveis de estrutura e textura uniformes, isto geralmente ocorre dois a três dias depois de uma chuva ou irrigação.

Quando o solo se encontra na CC, os macroporos estão livres de água e os microporos cheios. A classificação do diâmetro dos poros, proposta por Richards (1965) e Estados Unidos (1972), define micro e macroporos aqueles com diâmetro menor e maior que $0,05 \mathrm{~mm}$, respectivamente. Considerando-se que os macroporos são esvaziados no potencial matricial de -0,006 MPa, este pode ser utilizado para estimar a capacidade de campo.

O PMP é o teor de água do solo no qual as plantas experimentam perdas de turgescência das folhas e desta murcha não se recuperam quando colocadas em um ambiente escuro e saturado. O PMP representa, portanto, o teor de água mínima disponível no solo para o desenvolvimento das plantas (Briggs \& Shantz, 1912). Com base neste conceito, introduzido no início do século, o PMP é uma grandeza física de um solo, estimada pelo teor de água retida no potencial matricial de aproximadamente -1,5 MPa (Hillel, 1980; Romano \& Santini, 2002), pois em baixos potenciais matriciais o teor de água no solo varia pouco (Romano \& Santini, 2002). Para tal determinação em laboratório, utilizam-se as câmaras de Richards e, mais recentemente, um psicrômetro (WP4). A teoria, princípios e processos envolvidos na determinação do potencial com o WP4, podem ser encontrados em Scanlon et al. (2002). Contudo, o potencial da água no solo no PMP pode variar com a espécie, estádio fenológico da planta, histórico de estresse hídrico e condições ambientais (Slatyer, 1957; Carlesso, 1995; Romano \& Santini, 2002), sendo que a planta pode experimentar murcha permanente a potenciais variando de -0,8 a -2,0 MPa, ou mesmo -3,0 MPa. Outrossim, o potencial matricial da água do solo na proximidade da superfície das raízes pode ser até duas vezes mais baixo que a uma distância de $3 \mathrm{~cm}$ da raiz (Romano \& Santini, 2002).

O método direto ou fisiológico, empregado por Briggs \& Shantz (1912), é o padrão para determinar o PMP, mas é trabalhoso e exigente em tempo. Neste método, as amostras de solo, após serem destorroadas e peneiradas, são colocadas em vasos; em seguida, faz-se a semeadura, geralmente com girassol. O solo deve ser mantido em condições de teor de água próximo à capacidade de vaso, até que a planta tenha dois ou três pares de folhas; atingida esta condição, o umedecimento é suspenso e a superfície do solo coberta com cartolina parafinada, deixando-se apenas um orifício para a passagem da haste da planta. Quando houver murcha, a planta deverá ser colocada num ambiente úmido e escuro, durante $12 \mathrm{~h}$, cujo procedimento tem continuidade até que a planta atinja a sua murcha máxima e irreversível, sendo esse teor de água do solo considerado PMP.

Utilizando cinco espécies vegetais, Sykes (1969) determinou o PMP de dois solos e encontrou valores de -0,7 MPa, para girassol (Helianthus annuus L.), -3,47 MPa para canela (Cassia fasciculata Michs.) e -3,9 MPa para capim trigo (Agropyron intermedium Host.). Somente o tabaco, em solo francoargilo-siltoso, e o milho, em solo franco, apresentaram resultados relativamente próximos do esperado (-1,5 MPa), evidenciando diferenças altamente significativas entre solos, espécies e adaptação das plantas ao ambiente. O autor destaca que o principal fator determinante da murcha permanente da planta é a taxa de movimento de água através do solo até as raízes, como van Lier \& Libardi (1997) também o comprovaram para a cultura do arroz.

Apesar da relevância do tema para o manejo da água do solo e de sistemas de irrigação, são escassos os trabalhos que quantificam a água disponível com base no ponto de murcha fisiológica, particularmente para solos e condições brasileiras (Oliveira \& Martins, 1966; Cirino \& Guerra, 1994; Souza et al., 2002). Para solos do Nordeste brasileiro, Oliveira \& Martins (1966) observaram que o feijão-caupi, usado como planta indicadora, induziu a obtenção de valores de PMP inferiores a -1,5 MPa. Usando a mesma planta indicadora em solos com distintas classes texturais, Cirino \& Guerra (1994) encontraram valores de PMP significativamente inferiores para o método fisiológico comparado à retenção de água no potencial matricial de -1,5 MPa. Souza et al. (2002) obtiveram maior faixa de água disponível no método direto, o qual considera o PMP fisiológico, comparado ao método de laboratório.

Este trabalho foi realizado com o objetivo de se comparar os valores de teor de água na CC e no PMP e a água disponível, determinados por distintos métodos em um Latossolo argiloso, no campo e no laboratório, com e sem plantas de milho e girassol.

\section{MATERIAL E MÉTODOS}

Amostras de solo de um Latossolo Vermelho foram coletadas na profundidade de 0 a $0,2 \mathrm{~m}$, secadas ao ar e peneiradas em tamiz de $2 \mathrm{~mm}$. Detalhes do histórico das áreas são apresentados em Klein \& Libardi (2002). Este solo possui uma composição granulométrica média de $0,640 \mathrm{~kg} \mathrm{~kg}^{-1}$ de argila, $0,076 \mathrm{~kg} \mathrm{~kg}^{-1}$ de silte e $0,284 \mathrm{~kg} \mathrm{~kg}^{-1}$ de areia, com predominância das frações areia média (33\%) e areia fina (45\%), média de 2,33\% de matéria orgânica e apresenta, como característica importante, a microagregação.

O teor de água do solo na CC foi determinada considerando-se os limites de água retida no (i) potencial matricial (PM) de -0,006 MPa, (ii) PM de -0,008 MPa, (iii) PM de -0,01 MPa, (iv) PM de -0,033 MPa e (v) drenagem interna minimizada. Para as quatro principais determinações usaram-se amostras com estrutura alterada, as quais foram 
saturadas e submetidas à tensão equivalente especificada, utilizando-se funis de placa porosa, até a tensão de 0,01 MPa e Câmara de Richards para tensão de 0,03 MPa e, depois de cessada a drenagem, foi quantificada a água retida no solo. Para a drenagem interna, usou-se o método do perfil instantâneo, descrito por Hillel et al. (1972) e modificado por Libardi et al. (1980). Neste caso, o teor de água do solo da CC foi considerado quando a drenagem foi praticamente cessada, o que, em geral, ocorreu entre 2 a 3 dias após a inundação e toda a lâmina ter infiltrado, condição em que o PM se situava em torno de -0,08 MPa, valor este assumido por Klein (1998) como PM para CC.

O teor de água retida no PM de -1,5 MPa, definida como PMP, foi determinada em laboratório; para tanto, anéis com dimensões $73 \mathrm{~mm}$ diâmetro e $24 \mathrm{~mm}$ de altura foram preenchidos com terra peneirada (TFSA). Essas amostras foram saturadas com água destilada e submetidas à tensão de 1,5 MPa até o equilíbrio, utilizando-se câmaras de Richards, conforme descrito em Klein (1998), determinando-se o teor de água gravimetricamente. O teor de água do solo nesta tensão foi também estimada a partir de curva de retenção determinada pelo WP4 Dewpoint PotentiaMeter (Decagon, 2003).

O WP4 consta de um sistema cuja gaveta conduz uma amostra de solo úmido, com estrutura deformada, para dentro de uma câmara que fica hermeticamente fechada. A umidade na câmara equilibra-se com o potencial da água no solo, sendo este calculado com base na temperatura do solo e na do ar, no ponto de orvalho. As amostras de solo são previamente umedecidas, atingindo ampla faixa de variação de teor de água do solo e levadas ao aparelho. Cada determinação de potencial, para dado teor de água do solo, toma cerca de 5 min e se leva cerca de 2 h para determinação de aproximadamente vinte pontos, para construção da curva de retenção de água no solo. A variação do potencial empregado neste método foi de cerca de -0,030 até -3,0 MPa, situando-se na parte exponencial da curva de retenção de água. Com a curva de retenção de água no solo assim obtida, ajusta-se uma equação e se obtém o teor de água do solo à base de massa, para o potencial de -1,5 MPa ou outra de interesse (Decagon Devices, 2000).

Para determinação do PMP fisiológico, utilizaram-se vasos com capacidade de $1 \mathrm{~L}$, para implantação das culturas do milho e do girassol. Essas culturas foram semeadas e, quando as plantas possuíam três pares de folhas, a superfície dos vasos foi impermeabilizada, utilizandose papel alumínio, suspendendo-se, porém, o fornecimento de água. Quando as plantas perdiam a turgescência, eram recolhidas e colocadas em ambiente escuro e úmido. Quando não mais recuperavam a turgescência, foi determinado o teor de água do solo em três posições de cada vaso, realizando-se a média.

A água disponível foi estimada pela diferença entre a água na CC e no PMP, quantificados pelos distintos métodos de campo e de laboratório, com e sem planta indicadora.

A análise estatística constou da determinação, para os valores de CC, PMP e AD, da mediana, dos extremos, dos outliers e do percentil 25 e $75 \%$ e análise pelo teste $t$.

\section{RESULTADOS E DISCUSSÃO}

O teor de água médio do solo, de $0,378 \mathrm{~kg} \mathrm{~kg}^{-1}$, no potencial matricial de -0,006 MPa, foi estatisticamente superior ( $\mathrm{P}=0,0001)$ aos demais PM e métodos de determinação (Figura 1). De forma semelhante, o teor de água do solo no PM de -0,008 MPa diferiu dos demais ( $\mathrm{P}=0,005)$; o teor de água do solo de $0,342 \mathrm{~kg} \mathrm{~kg}^{-1}$ no PM de -0,01 MPa não diferiu daquela do método de drenagem sendo, no entanto, superior $(\mathrm{P}<0,0001)$ à obtida com -0,033 MPa, que foi de $0,293 \mathrm{~kg} \mathrm{~kg}^{-1}$; neste caso, para este Latossolo Vermelho, o potencial matricial que melhor descreve o teor de água do solo na CC, é -0,01 MPa.

Esses resultados indicam que a pressuposição apresentada na introdução deste artigo de que o teor de água do solo, quando os macroporos estão drenados (tensão de 0,006 MPa), seria um bom parâmetro para definir a CC, não é válida para este solo argiloso com boa agregação e porosidade, em função das outras forças envolvidas na dinâmica de retenção de água; assim, sem dúvida, a tensão com que todos os macroporos são drenados não é similar para todos os solos se usar o critério da inflexão da curva de retenção de água. Outrossim, a generalização de que a CC é o teor de água do solo a potenciais de -0,01 MPa para solos arenosos (Hillel, 1980; Romano \& Santini, 2002) e de -0,033 MPa (Hillel, 1980) até -0,05 MPa (Romano \& Santini, 2002) para solos argilosos também não é válida, particularmente para solo argiloso, com predominância de argilas 1:1 e oxihidróxidos, com adequada agregação e porosidade.

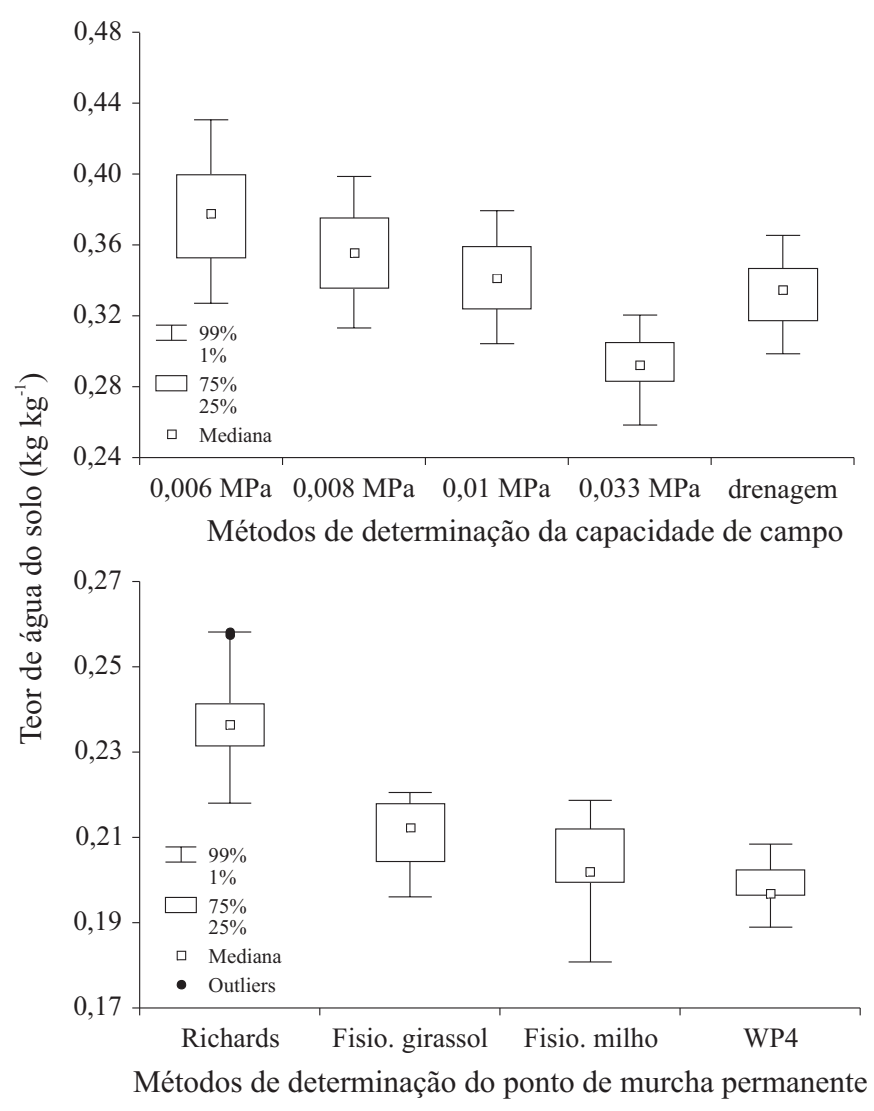

Figura 1. Teor de água do solo para diferentes tensões da água no solo na capacidade de campo (CC) e ponto de murcha permanente (PMP), determinados por distintos métodos no laboratório e no campo 
O teor de água do solo no qual ocorre o ponto de murcha fisiológico das plantas foi significativamente menor que aquele obtido com as câmaras de Richards em potencial de -1,5 MPa (Figura 1). A diferença entre os valores varia de 2 a $4 \%$, sendo maior para a cultura do milho. Esta diferença, contudo, é pequena e bem menor que aquela encontrada por Sykes (1969), reafirmando que a determinação do PMP em laboratório, utilizando-se a tensão de 1,5 MPa, é uma metodologia que pode ser utilizada para determinação do volume de água armazenado no solo e disponível para as plantas, apesar de ser muito demorada e não considerar, como salientam Slatyer (1957), Carlesso (1995) e Romano \& Santini (2002), características vegetais e condições ambientais. O resultado também evidencia que as plantas foram capazes de extrair água a potenciais mais baixos que -1,5 MPa ou que o equilíbrio potencial versus teor de água do solo não foi atingido nas amostras submetidas a tensão, nas placas porosas na câmara de Richards.
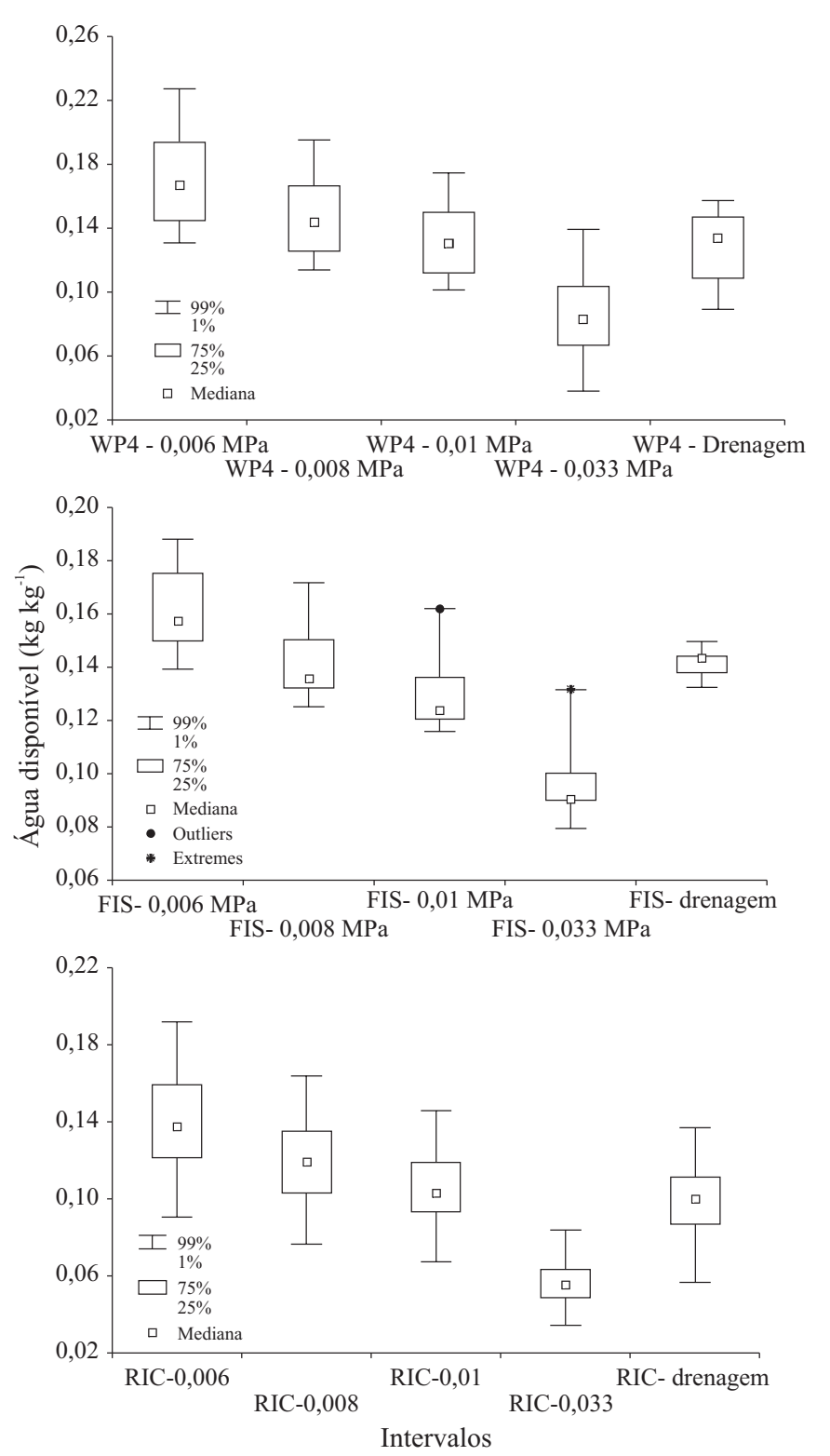

Figura 2. Água disponível entre distintos métodos de determinação da CC e o PMP determinado pelo WP4; CC e o método fisiológico (média girassol e milho) e o PMP método da câmara de Richards (1,5 MPa)
O valor do PMP obtido com o WP4, em torno de $0,20 \mathrm{~kg} \mathrm{~kg}^{-1}$, está mais próximo do teor de água do solo em que as plantas atingiram a murcha fisiológica, do daquele obtido com a câmara de Richards. Para a cultura do girassol não houve diferença estatisticamente significativa e, para as plantas de milho, esta diferença foi significativa $(P=0,013)$. Referidos resultados demonstram que o WP4 se apresenta como boa alternativa para determinação do PMP em solos, com muito mais rapidez que na câmara de Richards. Como nos dois métodos de determinação do PMP (WP4 e placa porosa) foram utilizadas amostras com estrutura deformada, a diferença nos resultados não se deve à alteração da porosidade, a qual não tem, segundo Campbell \& Gardner (1971), efeito marcante em baixos potenciais (-1,5 MPa); possivelmente por ser muito lenta nesse potencial, a drenagem do solo pode ser incompleta e o equilíbrio teor de água do solo versus potencial não ser alcançado (Gee et al., 2002).

A água disponível às plantas, em todos os cenários considerados (isto é, uso de distintos limites para CC), obtida pelo método fisiológico, não foi significativamente diferente daquela obtida pelo WP4 (Figura 2). O valor da água disponível para o método de determinação do PMP com a câmara de Richards foi estatisticamente diferente aos demais métodos, em todas as simulações. Independentemente do método de quantificação do limite inferior de disponibilidade de água às plantas, a água disponível diminuiu com o aumento na tensão usada para estimar a CC.

\section{CONCLUSÕES}

1. O teor de água do solo na capacidade de campo determinada diretamente no campo após $48 \mathrm{~h}$ de drenagem foi semelhante àquele no potencial matricial de -0,01 MPa em amostras equilibradas no laboratório usando-se funis de placa porosa.

2. O ponto de murcha permanente das plantas, para as duas culturas, foi significativamente menor no método fisiológico que o determinado nas câmaras de Richards.

3. A água disponível foi semelhante para os métodos WP4 e fisiológico.

4. O WP4 permitiu adequada estimativa do ponto de murcha permanente e disponibilidade hídrica às plantas, em solo argiloso.

\section{LITERATURA CITADA}

Briggs, L. J.; Shantz, H. L. The wilting coefficient for different plants and its indirect determination. Washington DC: Department of Agriculture, Bureau of Plant Industries, 1912, Bulletin $n^{0} 30,83 p$.

Campbell, G. S.; Gardner, W. H. Psycrometric measurement of soil water potential temperature and bulk density effects. Soil Science Society of America Journal, Madison, v.35, p.8-12, 1971.

Carlesso, R. Absorção de água pelas plantas: Água disponível versus extraível e a produtividade das culturas. Ciência Rural, Santa Maria, v.25, p.183-88, 1995. 
Cirino, C. G.; Guerra, H. O. C. Utilização das relações energia/ umidade na caracterização físico-hídrica dos solos. Pesquisa Agropecuária Brasileira. Brasília, v.29, p.1973-1978, 1994.

Decagon Devices. Operator's manual version 1.3 WP4 dewpointmeter. USA, Decagon Devices. 2000, 70p.

Decagon, (http://www.decagon.com/manuals/WP4man21.pdf). 18 Ago. 2003.

Estados Unidos. Department of Agriculture. Soil Conservation Service. Soil Survey Laboratory. Methods and procedures for collecting soil samples: Soil survey investigations. Washington; USDA/NRCS, 1972, 73p. Report 1

Gee, G. W.; Ward, A. L.; Zhang, Z. F.; Campbell G. S.; Mathison, J. The influence of hydraulic nonequilibrium on pressure plate data. Vadose Zone Journal, Madison, v.1, n.p.172-78, 2002.

Hillel, D. Fundamentals of soil physics. New York: Academic Press, 1980. 413p.

Hillel, D.; Krentos, V. D.; Stylianou, Y. Procedure and test of an internal drainage method for measuring soil hydraulic characteristics in situ. Soil Science, Baltimore, v.114, p.395-400, 1972.

Klein, V. A. Propriedades físico-hídrico-mecânicas de um latossolo roxo, sob diferentes sistemas de uso e manejo. Piracicaba: ESALQ/USP, 1998. 150p. Tese Doutorado

Klein, V. A.; Libardi, P. L. Densidade e distribuição do diâmetro dos poros de um Latossolo Vermelho, sob diferentes sistemas de uso e manejo. Revista Brasileira de Ciência do Solo, Viçosa, v.26, n.4, p.857-867, 2002

Libardi, P. L.; Reichardt, K.; Nielsen, D. R.; Biggar, J. W. Simple field methods for estimating soil hidraulic conductivity. Soil Science Society of America Journal, Madison, v.44, p.3-7, 1980

Oliveira, L. D. de; Martins, A. M. C. M. Considerações sobre a umidade de 15 atmosferas e a umidade de murcha (método fisiológico), em solos do Nordeste. Pesquisa Agropecuária Brasileira. Rio de Janeiro, v.1, p.91-95, 1966.
Reichardt, K. Capacidade de campo. Revista Brasileira de Ciência do Solo, Campinas, v.12, p.211-216, 1988.

Richards, L. A. Physical conditions of water in soil. In: Black, C. A. (ed.) Methods of soil analysis. Madison: American Society of Agronomy, 1965. p.128-152. Agronomy 9, Part 1.

Romano, I.; Santini, A. Water retention and storage: Field. In: Dane, J. H ; Topp, C. (Eds.) Methods of soil analysis. Part 4. Physical methods. Madison, Soil Science Society of America, 2002.p.721-38

Scanlon, B. R.; Andraski, B. J.; Bilskie, J. Water potential: Miscellaneous methods for measuring matric or water potential. In: Dane, J. H; Topp, C. (eds.) Methods of soil analysis. Part 4. Physical methods. Madison, Soil Science Society of America, 2002. p.643-670

Slatyer, R. O. The significance of the permanent wilting percentage in studies of plant and soil water relations. Botanical Review, New York, v.23, p.585-636, 1957.

Souza, C. S.; Oliveira, F. A.; Silva, I. F.; Amorim Neto, M. S. Avaliação de métodos de determinação de água disponível em solo cultivado com algodão. Pesquisa Agropecuária Brasileira. Brasília, v.37, p.337-341, 2002.

Souza, L. D.; Reichardt, K. Estimativas da capacidade de campo. Revista Brasileira de Ciência do Solo, Campinas, v.20, p.183189, 1996.

Sykes, D. J. Reconsideração do conceito da umidade de murchamento permanente. Turrialba, San José, v.19, p.525-530, 1969.

Van Lier J., Q. de; Libardi, P. L. Extraction of soil water by plants: Development and validation of a model. Revista Brasileira de Ciência do Solo, Campinas, v.212, n.4, p.535-542, 1997.

Veihmeyer, V. J.; Hendrickson, A. H. Methods of measuring field capacity and wilting percentage of soils. Soil Science, Baltimore, v.68, p.75-94, 1949. 